\title{
Density Functional Theory Studies of Structural Properties and Natural Bond Orbital for a New Silver Halo Compound
}

\author{
Shahriar Ghamami, Amir Lashgari \\ Department of Chemistry, Faculty of Science, Imam Khomeini International University, Qazvin, Iran \\ Email: ikiu2014@gmail.com
}

Received 10 April 2014; revised 20 May 2014; accepted 28 May 2014

Copyright (C) 2014 by authors and OALib.

This work is licensed under the Creative Commons Attribution International License (CC BY). http://creativecommons.org/licenses/by/4.0/

c) (i) Open Access

\begin{abstract}
In this theoretical study we used density functional theory to calculate the molecular structures of Silver Halo compound, $\mathbf{A g F}_{3}$. The molecular geometry, vibrational frequencies, energies and natural bond orbital (NBO) in the ground state are calculated by using the DFT (B3LYP) methods with LANL2DZ. The T.S guesses were generated by the linear synchronous transit method, at the DFT implemented on Gaussian 98 program. The geometries and normal modes of vibrations obtained from B3LYP calculations are in good agreement with the experimentally observed data.
\end{abstract}

Keywords

Theoretical Studies, Silver Halo Compound, Gaussian 98, AgF 3 , DFT

\section{Introduction}

Silver is a rare but naturally occurring element. It is slightly harder than gold and is very ductile and malleable [1]-[3]. Pure silver has the highest electrical and thermal conductivity of all metals and has the lowest contact resistance. Because of these properties, silver has been used in a wide variety of applications. Ancient civilizations were aware of silver's bactericidal properties. Metallic silver was used for surgical prosthesis and splints, fungicides, and coinage. Soluble silver compounds, such as silver salts, have been used in treating mental illness, epilepsy, nicotine addiction, gastroenteritis, and infectious diseases, including syphilis and gonorrhea.

Silver and its compounds can create ill-health through inhalation and contact with skin, nose, throat and eyes. Halo compounds are used in different fields of chemistry and industry. Particularly the fluorides have been subject of an intense scientific discussion since the first synthesis of such a compound. This is because of the important prerequisites for fluorinating agents to be useful, which are their mildness, versatility, selectivity and 
operational simplicity. The subject of this investigation is prepared inorganic fluorides and complexes. The halo compounds have been utilized in bioinorganic chemistry as reagents for synthesizing some model compounds, such as $\mathrm{AgF}_{3}$. The unique properties of halide impart an unusual reactivity to the fluoride bonds which can be exploited in preparative inorganic chemistry or in catalysis.

In recent years there has been a great deal of interest in the halo compounds. Investigation of the structures and properties of these compounds and their similarities are interested. Silver halides, especially flour compounds, have many used in theoretical and industrial. Many different data have been found about the structural properties of flour compounds, but they are insufficient and opposing in somewhere. A primitive synthesized flour Silver compound is $\mathrm{AgF}_{3}$, which is used for structural chemistry studies and organic synthesis. Theoretical calculations have been used for extraction of structural and electronically data of many compounds especially flour compounds. We applied the DFT method to optimizing and calculating molecular data of synthesized compounds. The calculation was done by using the Gaussian 98 [4] programs AD (1993), Becke For DFT, Becke's three-parameter exchange functional CT (1988), Lee was used in combination with the Lee-Yang-Parr correlation functional (B3LYP) with LANL2DZ basis set. Seppelt synthesized a new Silver compound and in this paper we investigated other properties of its [5]-[12].

\section{Material and Method}

\section{Computational Method}

All computational are carried out using Gaussian 98 program which combines the exact Hartree-Fock exchange with Becke's and uses the Lee-Yang-Parr correlation function in order to include the most important correlation effects. The structures of the molecules were completely optimized without any symmetry in all the levels. The optimized structural parameters were used in the vibrational frequency calculations at the DFT levels to characterize all stationary points as minima. Infrared intensities (int) in Kilometer per mole of all compounds were performed at the same level on the respective fully optimized geometries. These compounds and their data are in accordance with recent works on the formation of four coordinate intermediates.

\section{Results}

The Silver Halo compound, $\mathrm{AgF}_{3}$, was studied and geometry optimization was performed at the B3LYP/ LANL2DZ level and is shown in Figure 1. The $\mathrm{AgF}_{3}$, in which Fis bonded to the Ag atom, has a linear F-Ag structure with bond length (1.2) $1.98 \AA$, (1.3 - 1.4) $1.94 \AA$ and has a bent F-Ag-F structure with a bond angle $(2,1,3-2,1,4) 136.77^{\circ},(3,1,4) 86.44^{\circ}$ and dihedral angle $(2,1,4,3) 180^{\circ}$. Selected bond distances are illustrated in Figure 1, this structure show that this compound have $\mathrm{C}_{2 \mathrm{v}}$ symmetry.

Both the highest occupied molecular orbital (HOMO) and lowest unoccupied molecular orbital (LUMO) are the main orbitals that take part in chemical stability. The HOMO represents the ability to donate an electron, LUMO as an electron acceptor represents the ability to obtain an electron the HOMO and LUMO energy calculated by B3LYP at LANL2DZ method with transparent format scaled by 1.000000 showed in Figure 2. This electronic absorption corresponds to the transition from the ground to the first excited state and is mainly described by one electron excitation from the highest occupied molecular or orbital (LUMO).

Vibrational spectroscopy is widely used in organic and inorganic chemistry for the identification of functional groups (Raman spectra is used as a matching IR spectrum). The calculated data of the vibrational spectrum (FT-IR and FT-RAMAN) of $\mathrm{AgF}_{3}$ are given in Table 1.

This table showed that except tow frequencies, in other frequencies both IR and RAMAN spectrum are active, so its show that the $\mathrm{AgF}_{3}$ has nonsymmetrical structure. The calculated infrared spectra and Raman spectra for B3LYP/LANL2DZ basis sets of are presented together in Figure 3.

In this calculation maximum six vibration spectrum showed for this compound that the vectors of vibrations showed in Figure 4.

Atomic charges and bond orders are significant parameters for our investigation. These quantities are derived from the NBO population analysis. The NBO method is preferred to Mulliken charges, because the former provides an orbital picture that is closer to the classical Lewis structure. The NBO analysis involving atomic charges, bond orders as well as hybridizations of selected bonds are calculated at B3LYP/LANL2DZ level (Table 2). 


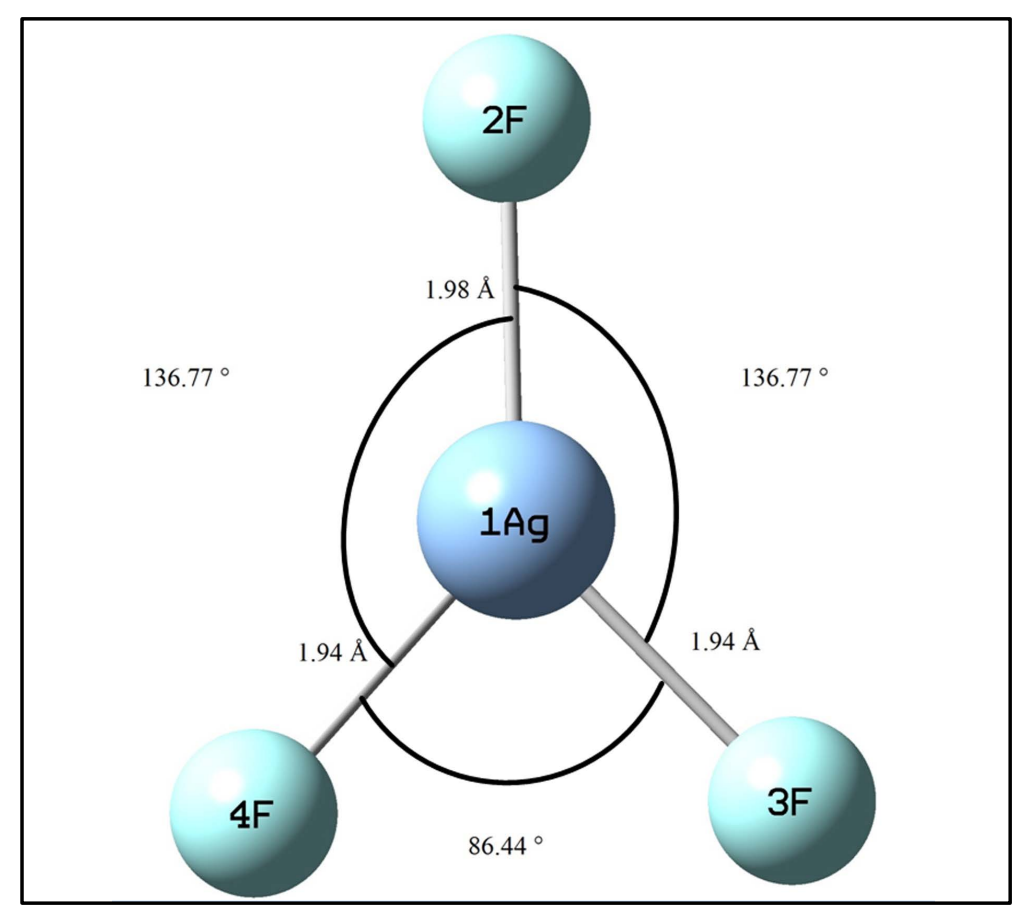

Figure 1. Optimized geometries of $\mathrm{AgF}_{3}$ at B3LYP/LANL2DZ level of thoery.

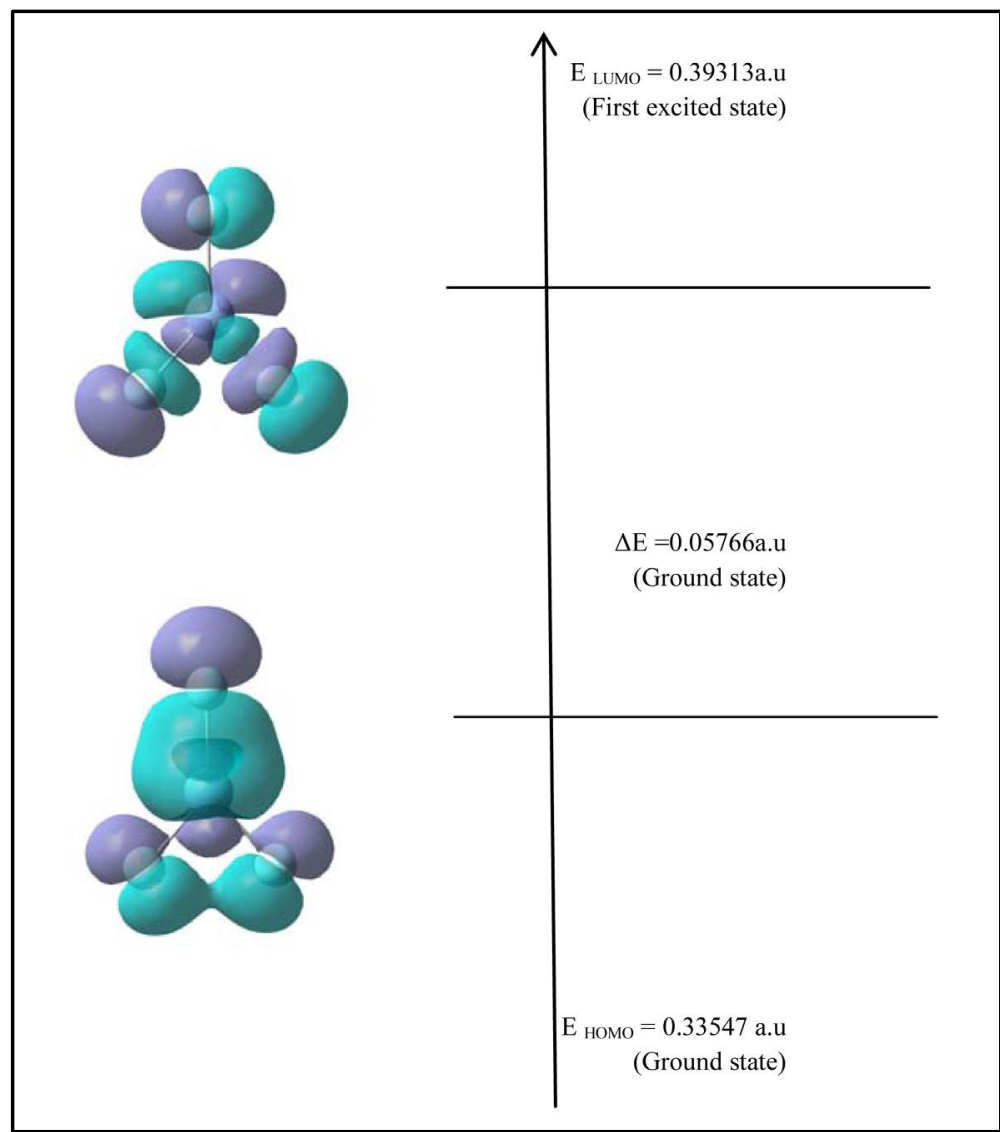

Figure 2. The atomic orbital compositions of the frontier molecular orbital with the transparent format scaled by 1.000000 for $\mathrm{AgF}_{3}$. 
Table 1. The vibrational frequencies calculated with B3LYP/LANL2DZ basis set for $\mathrm{AgF}_{3}$.

\begin{tabular}{ccc}
\hline & B3LYP/LANL2DZ & \\
\hline Frq $\left(\mathrm{cm}^{-1}\right)$ & FT-IR & FT-RAMAN \\
-3047.59 & 7112.47 & 0.01 \\
25.38 & 26.16 & 772563.40 \\
73.49 & 3.87 & 0.00 \\
528.02 & 61.28 & 741.82 \\
562.18 & 2.36 & 269.25 \\
649.20 & 24.91 & 138806.13 \\
\hline
\end{tabular}

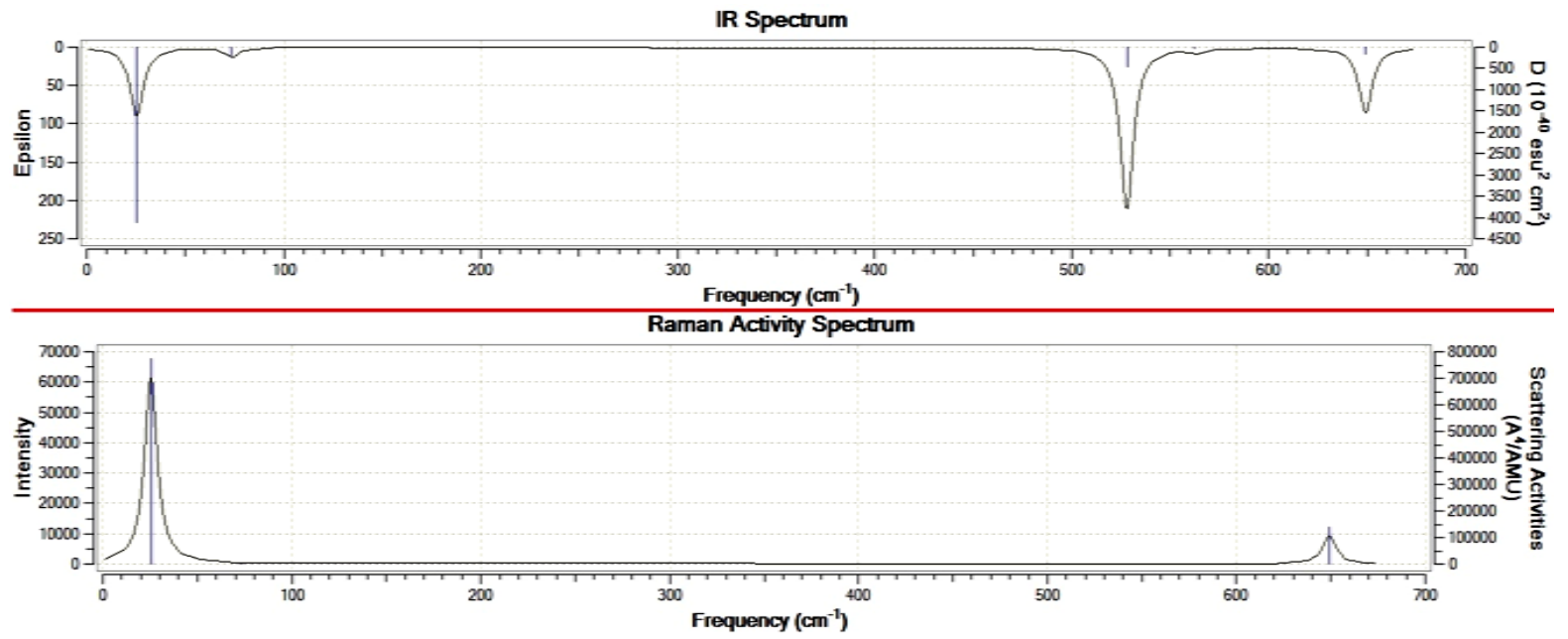

Figure 3. The calculate FT-IR and FT-RAMAN spectrum for $\mathrm{AgF}_{3}$.

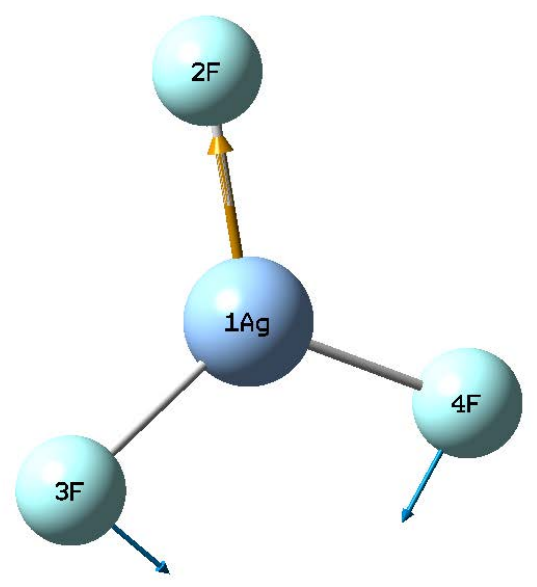

Figure 4. The vector of vibration spectrum for $\mathrm{AgF}_{3}$.

Second order perturbation theory analysis of Fock matrix in NBO basis for $\mathrm{AgF}_{3}$ is shown in Table 3 .

Computational (theoretical) calculations energy differences for the compounds were determined by optimizing the geometry at various computational levels. Comparison of the energies at the B3LYP/LANL2DZ level is shown in Table 4. 
Table 2. The NBO calculated hybridization for $\mathrm{AgF}_{3}$.

\begin{tabular}{cccccc}
\hline $\mathrm{E} \sigma$ & Bond (BD) & Hybridization & $\mathrm{E} \cdot \sigma^{*}$ & Bond (BD*) & Hybridization \\
\hline 1.99 & $\mathrm{Ag}(1)-\mathrm{F}(2)$ & $\mathrm{s}^{61.54} \mathrm{p}^{36.63} \mathrm{~d}^{1.83}$ & 0.05 & $\operatorname{Ag}(1)-\mathrm{F}(2)$ & $\mathrm{s}^{61.54} \mathrm{p}^{36.63} \mathrm{~d}^{1.83}$ \\
1.78 & $\mathrm{Ag}(1)-\mathrm{F}(3)$ & $\mathrm{s}^{18.3} \mathrm{p}^{31.21} \mathrm{~d}^{50.49}$ & 0.36 & $\operatorname{Ag}(1)-\mathrm{F}(3)$ & $\mathrm{s}^{18.3} \mathrm{p}^{31.21} \mathrm{~d}^{50.49}$ \\
1.78 & $\mathrm{Ag}(1)-\mathrm{F}(4)$ & $\mathrm{s}^{18.3} \mathrm{p}^{31.21} \mathrm{~d}^{50.49}$ & 0.36 & $\operatorname{Ag}(1)-\mathrm{F}(4)$ & $\mathrm{s}^{18.3} \mathrm{p}^{31.21} \mathrm{~d}^{50.49}$ \\
\hline
\end{tabular}

Table 3. Secend order perturbation theory analysis of Fock matrix in $\mathrm{NBO}$ basis for $\mathrm{AgF}_{3} \cdot{ }^{\mathrm{a}} \mathrm{E}(2)$ means energy of hyper conjugative interaction (stabilization energy); ${ }^{b}$ Energy difference between donor and acceptor I and j NBO orbital's; ${ }^{\text {c }} \mathrm{F}(\mathrm{i}, \mathrm{j})$ is Fock matrix element between I and j NBO orbital's.

\begin{tabular}{ccccccccc}
\hline Donor (i) & Type & ${ }^{*}$ ED/e & Acceptor (j) & Type & ${ }^{*} E D / e$ & $E(2)^{\mathrm{a}}(\mathrm{KJ} / \mathrm{mol})$ & $\mathrm{E}(\mathrm{j})-\mathrm{E}(\mathrm{i})^{\mathrm{b}}(\mathrm{a} . \mathrm{u})$ & $\mathrm{F}(\mathrm{i}, \mathrm{j})^{\mathrm{c}}(\mathrm{a} . \mathrm{u})$ \\
\hline $\mathrm{F} 2(1)$ & $\mathrm{n}$ & 0.99310 & $\mathrm{Ag}(6)$ & $\mathrm{n}^{*}$ & 0.11417 & 1.25 & 0.98 & 0.047 \\
F2(1) & $\mathrm{n}$ & 0.99310 & $\operatorname{Ag}(8)$ & $\mathrm{n}^{*}$ & 0.03071 & 4.04 & 0.97 & 0.08 \\
F2(2) & $\mathrm{n}$ & 0.98598 & $\operatorname{Ag}(9)$ & $\mathrm{n}^{*}$ & 0.03071 & 1.97 & 0.2 & 0.025 \\
F2(3) & $\mathrm{n}$ & 0.98251 & $\mathrm{Ag}(7)$ & $\mathrm{n}^{*}$ & 0.05172 & 2.19 & 0.18 & 0.026 \\
F2(4) & $\mathrm{n}$ & 0.95255 & $\mathrm{Ag}(8)$ & $\mathrm{n}^{*}$ & 0.03071 & 1.55 & 0.27 & 0.026 \\
\hline
\end{tabular}

*Electron density.

Table 4. Calculated ZPE (hartrees), energies (hartrees), enhalpies (hartrees), Gibbs Free Energies (hartrees) of $\mathrm{AgF}_{3}$.

\begin{tabular}{ccc}
\hline & ZPE & \\
\hline B3LYP & AgF $_{3}$ \\
\hline ZPE & -445.042 \\
E & -445.036 \\
H & -445.035 \\
G & -445.075 \\
\hline
\end{tabular}

\section{Discussions}

Silver is rare but is only found in nature, often by mining. Silver is a soft metal often used for making jewelry. It is also used for silverware, electronic equipment and dental fillings. Silver compounds can be found at hazardous waste sites mixed with soil and/or water. Silver compounds are used for the coating of photographic and X-ray film. Photography materials are the major source of discarded silver [13].

Silver can enter your body through your skin, such as photographers touching powders with silver in them. Some medicines containing silver are taken or put on the skin or gums. Much less silver will enter the body through the skin than through the lungs or stomach [14]. Many silver compounds dissolve in water. They do not turn into a vapor. If silver is eaten or inhaled, it leaves the body in waste matter in about a week. Some of the silver that is eaten inhaled, or passes through the skin may build up in many places in the body Density functional theory methods were employed to determine the optimized structure of $\mathrm{AgF}_{3}$. Initial calculations were performed at the DFT level and split-valence plus polarization LANL2DZ basis sets were used. Local minima were obtained by full geometrical optimization have all positive frequencies. All calculations were carried out using the computer program GAUSSIAN 98.

\section{Conclusion}

In this theoretical study we used density functional theory to calculate the molecular structures of Silver Halo compound compounds, $\mathrm{AgF}_{3}$. The molecular geometry, vibrational frequencies, energies and natural bond orbital (NBO) in the ground state are calculated by using the DFT (B3LYP) methods with LANL2DZ. The calculation 
results indicated that some selected bond length and bond angles value for the $\mathrm{AgF}_{3}$. Also calculated HOMO and LOMO energies showed small difference between both levels. And comparison between FT-IR and FT-RAMAN spectra showed that the $\mathrm{AgF}_{3}$ has nonsymmetrical structure.

\section{Acknowledgements}

We gratefully acknowledge the financial support from the Research Council of Imam Khomeini International University.

\section{References}

[1] Aaseth, J., Olsen, A. and Halse, J. (1981) Argyria-Tissue Deposition of Silver as Selenide. Scandinavian Journal of Clinical \& Laboratory Investigation, 41, 247-251. http://dx.doi.org/10.3109/00365518109092041

[2] Armitage, S.A., White, M.A. and Wilson, H.K. (1996) The Determination of Silver in Whole Blood and Its Application to Biological Monitoring of Occupationally Exposed Groups. The Annals of Occupational Hygiene, 40, 331-338. http://dx.doi.org/10.1093/annhyg/40.3.331

[3] Baldi, C., Minoia, C., Di Nucci, A., Capodaglio, E. and Manzo, L. (1988) Effects of Silver in Isolated Rat Hepatocytes. Toxicology Letters, 41, 261-268. http://dx.doi.org/10.1016/0378-4274(88)90063-X

[4] Frisch, J., Trucks, G.W., Schlegel, H.B., Scuseria, G.E., Robb, M.A. and Cheeseman J.R. (1998) GASSIAN 98 (Revision A.3). Gaussian Inc., Pittsburgh.

[5] Seppelt, K. and Sundermeyer, W. (1969) N-Halogen-Sulfinylamine. Naturwissenschaften, 56, 281-282. http://dx.doi.org/10.1007/BF00633932

[6] Seppelt, K. and Sundermeyer, W. (1969) Über Darstellung und Eigenschaften des Tetrakis-trimethyl-silyl-hydrazins und anderer silylsubstituierter Hydrazine. Chemische Berichte, 102, 1247-1252. http://dx.doi.org/10.1002/cber.19691020416

[7] Seppeltu, K. and Sundermeyer, W. (1969) Eineneue Methode zur Darstellung von Halogenaminen. Z. Naturf, 24b, 774-785.

[8] Seppeltu, K. and Eysel, H.H. (1971) Schwingungsspektrum und Kraftkonstanten des Tetrakis-trimethylsilyl-hydrazin, $\left[\left(\mathrm{CH}_{3}\right)_{3} \mathrm{Si}\right]_{2} \mathrm{~N}-\mathrm{N}\left[\mathrm{Si}\left(\mathrm{CH}_{3}\right)_{3}\right]_{2}$. Zeitschrift für Anorganische und Allgemeine Chemie, 384, 147-154. http://dx.doi.org/10.1002/zaac.19713840209

[9] Seppeltu, K. and Sundermeyer, W. (1970) Notiz über Metall-[tris(trimethylsilyl)-hydrazide]. Chemische Berichte, 103, 3939-3941. http://dx.doi.org/10.1002/cber.19701031228

[10] Seppelt, K and Sundermeyer, W. (1969) Über $N$-Halogenimidoschwefeldifluoride und $N, N$ '-Dihalogenschwefeldiimide. Angewandte Chemie, 81, 785-786. http://dx.doi.org/10.1002/ange.19690812012

[11] Seppeltu, K. and Sundermeyer, W. (1970) Neue Imidoschwefeloxiddifluoride. Angewandte Chemie, 82, 931-955. http://dx.doi.org/10.1002/ange.19700822204

[12] Seppelt, K. and Sundermeyer, W. (1971) N-Halogenimido schwefeloxiddifluoride. Z. Naturf, 26(b), 65-73.

[13] Johnson, J., Jirikowic, J., Bertram, M., Van Beers, D., Gordon, R.B. and Henderson, K. (2005) Contemporary Anthropogenic Silver Cycle: A Multilevel Analysis. Environmental Science \& Technology, 39, 4655-4665. http://dx.doi.org/10.1021/es048319x

[14] Singh, K., Barwa, M.S. and Tyagi, P. (2007) Synthesis and Characterization of Cobalt(II), Nickel(II), Copper(II) and Zinc(II) Complexes with Schiff Base Derived from 4-amino-3-mercapto-6-methyl-5-oxo-1,2,4-triazine. European Journal of Medicinal Chemistry, 42, 394-402. http://dx.doi.org/10.1016/j.ejmech.2006.10.016 